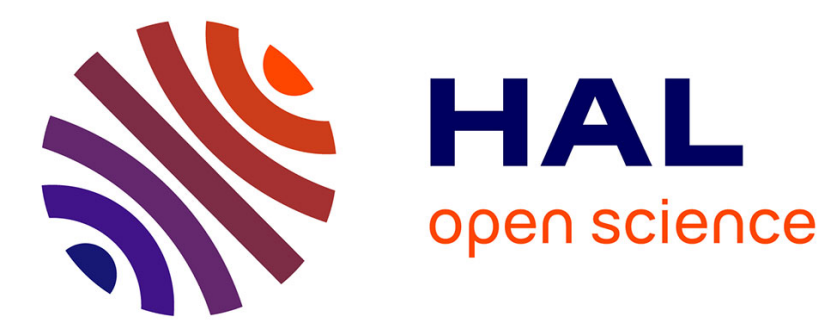

\title{
Long-term Evaluation of Porous PEGT/PBT Implants for Soft Tissue Augmentation
}

Evert N. Lamme, Daniel Druecke, Jeroen Pieper, Paul S. May, Peter Kaim, Frank Jacobsen, Hans-Ulrich Steinau, Lars Steinstraesser

\section{- To cite this version:}

Evert N. Lamme, Daniel Druecke, Jeroen Pieper, Paul S. May, Peter Kaim, et al.. Long-term Evaluation of Porous PEGT/PBT Implants for Soft Tissue Augmentation. Journal of Biomaterials Applications, 2008, 22 (4), pp.309-335. 10.1177/0885328207075552 . hal-00570777

\section{HAL Id: hal-00570777 \\ https://hal.science/hal-00570777}

Submitted on 1 Mar 2011

HAL is a multi-disciplinary open access archive for the deposit and dissemination of scientific research documents, whether they are published or not. The documents may come from teaching and research institutions in France or abroad, or from public or private research centers.
L'archive ouverte pluridisciplinaire HAL, est destinée au dépôt et à la diffusion de documents scientifiques de niveau recherche, publiés ou non, émanant des établissements d'enseignement et de recherche français ou étrangers, des laboratoires publics ou privés. 


\title{
Long-term Evaluation of Porous PEGT/PBT Implants for Soft Tissue Augmentation
}

\author{
Evert N. Lamme, ${ }^{1}$ Daniel Druecke, ${ }^{2}$ Jeroen Pieper, ${ }^{3}$ \\ Paul S. May, ${ }^{2}$ Peter KaIm, ${ }^{3}$ Frank Jacobsen, ${ }^{2}$ \\ HANS-UlRICH STEINAU ${ }^{2}$ AND LARS STEINSTRAESSER ${ }^{2, *}$ \\ ${ }^{1}$ Department of Dermatology, Radboud University Nijmegen Medical Center \\ St. Radboud Hospital, Nijmegen, The Netherlands \\ ${ }^{2}$ Department of Plastic Surgery, Burn Center, BG-University Hospital \\ Bergmannsheil, Ruhr University Bochum, Bochum, Germany \\ ${ }^{3}$ IsoTis OrthoBiologics, Bilthoven, The Netherlands
}

\begin{abstract}
Porous PEGT/PBT implants with different physico-chemical characteristics were evaluated to identify its potential as biodegradable and biofunctional soft tissue filler. Implants $\left(50 \times 10 \times 5 \mathrm{~mm}^{3}\right)$ were implanted subcutaneously in mini-pigs and tissue response, tissue volume generated and its consistency were assessed quantitatively with a 52 weeks follow-up. The absence of wound edema, skin irritation, and chronic inflammation demonstrated biocompatibility of all implants evaluated. The hydrophobic implants induced the mildest foreign body response, generated highest amount of connective tissue and demonstrated a decrease in copolymer MW of 34-37\% compared to $90 \%$ decrease of the hydrophilic implants. The rate and extent of copolymer fragmentation seems to be the determining factor of success of soft tissue augmentation using porous PEGT/PBT copolymer implants.
\end{abstract}

KEY WORDS: porous implants, soft tissue augmentation, biofunctionality, host response, tissue deposition.

\footnotetext{
*Author to whom correspondence should be addressed.

E-mail: lars.steinstraesser@ruhr-uni-bochum.de

Figures 3, 4 and 6 appear in color online: http://jba.sagepub.com
} 


\section{INTRODUCTION}

7 reatment of extensive soft tissue defects after trauma or cancer 1 therapy is accomplished with flap reconstruction or autologous free-fat grafting [1-6]. Both techniques have drawbacks such as donor site morbidity and the unpredictable behavior of fat grafts. In cases where only augmentation of soft tissue is required, the use of biodegradable porous implants mediating regeneration of connective tissue would be advantageous. The primary requirements of such implants are not only safety and biocompatibility, but also biofunctionality. The latter, although often disregarded, is as important as biocompatibility [7].

Biocompatibility is defined as the ability of a material to perform with an appropriate host response in a specific biomedical application [8]. The International Organization of Standardization in Geneva has presented the ISO 10993 standard as a guideline to evaluate safety and biocompatibility of biomedical devices. Biofunctionality, however, concerns the ability of the implant to perform the purpose for which it was designed. In subcutaneous tissue augmentation, the specific function of the device is to directly augment tissue to the normal skin level and preferably be biodegradable, porous, and generate tissue with similar quality and mechanical properties as the original, healthy tissue. To realize the latter, the implant should have an appropriate pore geometry (porosity, pore size, and interconnectivity), because this determines the rate of tissue ingrowth, amount of extracellular matrix deposition, and cell survival in the porous implants [9-11]. However, consistent long-term in vivo data about porous implant is sparse. One of the reasons for this is that implant biodegradability and porosity also adds complexity to the in vivo soft tissue biofunctionality evaluations. The changes in implant shape, structural integrity, or roughness over time are likely to negatively affect the local tissue response and connective tissue deposition. These changes in mechanical tissue irritation and alteration in degradation rate necessitates long-term biofunctionality studies and this study was conducted in view of this.

Elastomeric segmented polyether/polyester amphiphilic multiblock copolymers form a class of interesting biocompatible materials with unique properties [12]. Poly-(ethylene glycol) (PEG) is normally used as the hydrophilic segment, because of its non-toxicity, lack of immunogenicity, and its solubility in both organic solvents and water [13]. Furthermore, it has been shown that PEG $(\mathrm{MW}=6000 \mathrm{Da})$ is 
passively excreted through the kidneys. Therefore, various hydrophobic blocks have been used to obtain physically cross-linked biodegradable polymers, poly(butylene terephthalate) (PBT) proved to be a very interesting candidate, resulting in PEGT/PBT copolymers. By variation in the weight percentage and/or length of the soft and hydrophilic PEGT segment, copolymers can be prepared differing in hydrophilicity, pliability, mechanical integrity, degradation rate, and cell-adhesion affinity. Furthermore, the PEGT/PBT copolymer has already been introduced to the clinic as a degradable scaffold for the repair of tympanic membranes [14,15] more than 15 years ago. More recently the FDA approved it as a cement restrictor in orthopedics $[16,17]$. In the field of soft tissue regeneration, several polymer compositions have been shown in vitro to support adhesion and growth of skin cells and in vivo ingrowth of vessels and connective tissue [18-24]. These developments are supported by several in vitro and in vivo studies which showed that PEGT/PBT copolymers are biocompatible, well-tolerated, and do not cause adverse tissue reactions or systemic site effects $[15,21,25-30]$.

Based on its biocompatibility profile, several PEGT/PBT copolymer compositions were prepared to produce porous implants. These implants $\left(50 \times 10 \times 5 \mathrm{~mm}^{3}\right)$, differing in hydrophilicity and degradability, were implanted subcutaneously into mini-pigs for time periods up to 52 weeks to decide on the appropriate biofunctional implant for soft tissue filling. Mini-pigs were used because the anatomy and physiology of the porcine skin layer resembles the human skin best [31]. The polymer implant degradation rate and behavior was evaluated in relation to the intensity of the host tissue response, the amount and quality of tissue deposition in the pores of the implants, and tissue volume generated.

\section{MATERIALS AND METHODS}

\section{Synthesis of PEGT/PBT Copolymers}

PEGT/PBT block copolymers were synthesized in a two-step melt polycondensation procedure [32]. Briefly, the first step involves transesterification of dimethyl terephthalate (DMT) with PEG and an excess of 1,4 -butanediol at $\approx 200^{\circ} \mathrm{C}$. Titanium butoxide is used as a catalyst, $\alpha$-tocopherol as antioxidant, and methanol was removed by distillation. Polycondensation is performed at about $240^{\circ} \mathrm{C}$, using a vacuum to facilitate removal of the condensation product 1,4-butanediol. 
By varying the feed ratio of PEG to 1,4-butanediol, or the molecular weight (MW) of the hydrophilic PEG blocks, a family of polymers can be obtained. The chemical structure of the polymers is shown below. The copolymers are abbreviated as $a \mathrm{PEG} b \mathrm{PBT} c$, in which $a$ is the PEG MW, $b$ weight\% PEG-terephthalate, and $c$ the weight\% PBT.

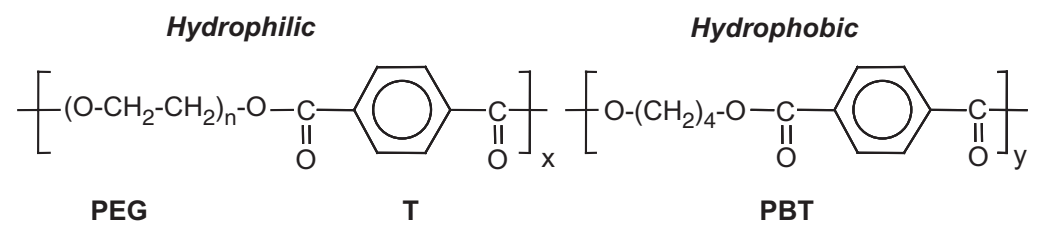

The following polymer compositions were synthesized and used to produce porous implants: 300PEGT55PBT45, 300PEGT70PBT30, 1000PEGT70PBT30, 4000PEGT55PBT45, and 2000PEGT80PBT20. The average MW of all copolymers ranged between 95 and $105 \mathrm{kDa}$ as determined by GPC, the glass transition and melting $T$.

\section{Preparation of Porous PEGT/PBT Implants}

Implants were manufactured using compression molding/porogen leaching technology, and processed and sterilized as intended for clinical product application. A homogeneous mixture of similar sized copolymer granules $(<400 \mu \mathrm{m}, 25 \mathrm{vol} \%)$ and sodium chloride with crystal grain sizes $500-600 \mu \mathrm{m}(75 \mathrm{vol} \%)$ were placed in a designed mold and compressed with a pressure of $10,000 \pm 500 \mathrm{lb} / \mathrm{in} .{ }^{2}$. The mold was heated up to $210 \pm 10^{\circ} \mathrm{C}$ for $5 \pm 0.5 \mathrm{~min}$. After cooling, salt leaching was performed in several changes of demineralized water. The porous blocks were dried at room temperature for $2 \mathrm{~d}$ and overnight in a $50^{\circ} \mathrm{C}$ vacuum oven. Implants were vacuum-sealed and sterilized with a dose of $25 \mathrm{k}$ Gray $\gamma$-irradiation.

\section{PEGT/PBT Implants Characteristics}

Implant water uptake was determined as a combination of water binding and sorption capacity. Implants of $1 \times 1 \mathrm{~cm}^{2}$ were incubated in PBS ( $\mathrm{pH} 7.4$ ) for $24 \mathrm{~h}$ at room temperature. Excess liquid was removed by placing the tip of the scaffold on a low absorption paper for $2 \mathrm{~s}$ and the wet weight was measured. The water uptake was expressed as a percentage of the corresponding initial dry weight. 
Scanning electron microscopy was used to evaluate implant morphology. Implants were mounted on stubs, sputtered with an ultra thin layer of gold in a Polaron E5100 SEM coating system. Specimens were studied with a Philips XL30 ESEM-FEG SEM apparatus at an accelerating voltage of $10 \mathrm{kV}$.

Scaffold porosity was evaluated using micro-computed tomography. Briefly, scaffolds were scanned at three different scaffold locations at $45 \mathrm{kVp}$ using the mCT-40 (Scanco Medical, Switzerland) at a resolution of $12 \mathrm{~mm}$. Three-dimensional scaffold reconstructions were created by stacking $2002 \mathrm{D}$ slices $(2048 \times 2048$ pixels $)$, allowing the evaluation of pore volume and ranged from 76 to $82 \%$ for all compositions.

A direct contact test was performed to measure cell attachment and growth as an indication for surface charge. Implants were equilibrated in fibroblast culture medium for $24 \mathrm{~h}$ and seeded statically with human fibroblasts at a density of 500,000 cells cm${ }^{-3}$. Fibroblasts were cultured in Dulbecco's modified Eagle's medium (DMEM, Invitrogen Life Technologies) containing $10 \%$ fetal bovine serum (FBS, Hyclone), penicillin $(100 \mathrm{U} / \mathrm{mL})$, and streptomycin $(100 \mathrm{mg} / \mathrm{mL})$ at $37^{\circ} \mathrm{C}, 5 \% \mathrm{CO}_{2}$. To evaluate cell attachment, distribution and increase in cell numbers implants were fixated after 24 and $96 \mathrm{~h}$ in $4 \%$ paraformaldehyde for $16-24 \mathrm{~h}$ at RT, stained en bloc with $1 \%$ methylene blue PBS solution, rinsed in an excess PBS, and analyzed using a stereomicroscope.

\section{Implantation Studies in Göttinger Mini-pigs}

The protocol was approved by the Ruhr-University of Bochum Committee of Animal Welfare. Seven female Göttinger mini-pigs $(25-30 \mathrm{~kg})$ were included in the study and received proper care as outlined in Guide for the Care and Use of Laboratory Animals. Animal anesthetics: before each surgical procedure, and bandage changing, the pigs were sedated by intramuscular injection with mixture of ketamine $10 \mathrm{mg} \mathrm{kg}^{-1}$ (Ratiopharm, Ulm, Germany) and midozalom $1 \mathrm{mg} \mathrm{kg}^{-1}$ (Curamed Pharma, Karlsruhe, Germany). Complete anesthesia was induced with a facemask with 5\% isoflurane and a 50:50 mixture of nitrous oxygen and oxygen ( $3-5 \mathrm{~L} / \mathrm{min})$. Anesthesia was maintained with 1-2\% isoflurane and the same air mixture. For the implantation surgery, $0.001 \mathrm{mg} \mathrm{kg}^{-1}$ atropine was included in the sedation solution. After complete anesthesia was induced, animals were intubated and artificial respiration was applied. During the operation, analgesia was provided by intravenous injection of Fentanyl $\left(0.4 \mathrm{~mL} \mathrm{~kg}^{-1}\right.$, Janssen Pharmaceuticals, Gent, Belgium). Vital functions were monitored 
and fluid loss was compensated by an intravenous infusion with Ringers solution. Post-operative pain was treated daily for $3-4 \mathrm{~d}$ with a subcutaneous injection containing flunixine $1 \mathrm{mg} \mathrm{kg}^{-1}$ per day (Finadyne ${ }^{\circledR}$, Schering-Plough, Segré, France).

On the day of operation, the hair was clipped from both dorsal flanks and the skin was disinfected with Hibiscrub, $70 \%$ alcohol solution containing $0.6 \%$ chlorohexidin, and $2 \%$ iodine solution. For the implantation studies, the ASTM guideline F1408-97 Standard Practice for Subcutaneous Screening Test for Implant Materials, ASTM F1983-99 Standard Practice for Assessment of Compatibility of Absorbablel Resorbable Biomaterials for Implant Applications, and ISO 10993-6 standard 'Tests for local effects after implantation' were followed. After a surgical incision of $4-5 \mathrm{~cm}$ until the deepest subcutaneous fat layer on both flanks 12 subcutaneous pockets were created in the middle of the adipose layer using blunt scissors. Each treatment group including a sham control was applied 4 times in each animal in a randomized fashion. Implant size before hydration was $50 \times 10 \times 5 \mathrm{~mm}^{3}$. The wounds were sutured and dressed with a non-adherent gauze (Melonin, Smith \& Nephew, Hull, UK) fixed with an adhesive tape. Protection against mechanical trauma was achieved by wound coverage with one layer of hydrophilic gauzes $\left(5 \times 5 \mathrm{~cm}^{2}\right)$ fixed with adhesive tape, two layers of hydrophilic gauzes $\left(20 \times 20 \mathrm{~cm}^{2}\right)$ fixed with elastic adhesive tape from the back to the midriff/abdomen, and elastic bandage. The pigs were housed individually, fed, and monitored twice a day. After $7 \mathrm{~d}$, bandage and stitches were removed. Implant areas were scored for skin irritation (redness), edema, and/or hematoma formation. The investigators on regular basis monitored the animal behavior with weekly intervals in the beginning and biweekly after 6 weeks.

\section{Macroscopic Evaluations}

At each evaluation time point $(4,12,26$, and 52 weeks), the implantation site was scored for color and tissue consistency according to the following scheme: color (pink as surrounding skin 1; red 2; purple 3); tissue consistency (supple as surrounding skin 1; stiff 2; hard fibrotic scar-like tissue 3) and tissue volume generated (maximum skin augmentation similar to moment of implantation 1 ; some skin augmentation 2; no skin augmentation anymore 3 ). The latter observations and scores were confirmed during the implant explantation procedure. Before the implants were removed with the intact tissue envelope, they were digitally photographed and scored for tissue 
ingrowth/consistency as described above. Abnormalities in surrounding tissue or implants were recorded separately.

\section{Microscopic and TEM Evaluations}

For light microscopic (LM) evaluation, the implants $(n=4$ per composition) were fixated in $4 \%$ formaldehyde for $48-96 \mathrm{~h}$ at RT. Hereafter samples were cut into three parts as indicated in Figure 1. Parts I and II were dehydrated, embedded in paraffin, and serial sections were cut from the sides indicated in Figure 1. The serial sections were used for Sirius red, hematoxilin and eosin, and von Kossa staining to identify ECM deposition, cell infiltration, and calcified tissue/polymer parts, respectively. Implant part III was prepared for transmission electron microscopy (TEM). The samples were fixated in 1.5\% glutaraldehyde in $0.1 \mathrm{M}$ cacodylate buffer $(\mathrm{pH} 7.4)$ at $4^{\circ} \mathrm{C}$ for at least $4 \mathrm{~d}$ and post-fixated in a solution of $1 \% \mathrm{OsO}_{4}$ and $1.5 \% \mathrm{~K}_{4} \mathrm{Fe}(\mathrm{CN})_{6}$. After dehydrating and embedding in Epon, ultrathin sections were cut and stained with uranyl acetate and lead citrate. In the second implantation study, one-third of the explanted implant was cut off and frozen to measure implant degradation (Figure 1: part for GPC).

\section{Histological Identification of Different Cell Types}

To identify vessels, sections were stained with a polyclonal antibody against von Willebrand factor (Dako) as described earlier [33]. Stromal cells (fibroblasts) and macrophages were identified with a double staining for vimentin (clone V9, Dako) and monocytes/macrophages (clone MAC387, Serotec) using the appropriate Vectastain kits according to the manufacturers instructions and visualized using Vecta red and blue substrate, respectively (Vector Laboratories). All sections were labeled after antigen retrieval using heat treatment according to the manufacturers.

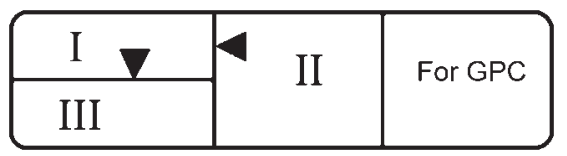

Figure 1. Schematic overview of implants and its post-retrieval division for analysis. Part I and II were fixated and embedded in paraffin, part III was used for TEM analysis, and part IV was frozen and used for MW GPC and 1H-NMR analysis. 


\section{Quantification of Cell Numbers, Host Tissue Response, and Tissue Ingrowth}

Identifications on the object glasses were covered. Three representative digital images $(172 \times 86 \mu \mathrm{m})$ were taken of $\mathrm{H} \& \mathrm{E}$ and vimentinmacrophages double stained sections at different locations in the cross section of implant part II ( $n=5$ per group). Areas with large vessels or large polymer fragments were avoided. Sections were analyzed and cells were counted in a blinded fashion. The degree of inflammation/tissue response was analyzed by counting the different cell types expressed as percentage of total infiltration cells. In double stained sections, single red positive cells were counted as fibroblast and double positive red and blue (purple) cells were counted as macrophages. In serial sections stained with H\&E, multi-nucleated cells were counted as giant cells, white blood cells containing granules as granulocytes, and total cell numbers by counting all nucleated cells (giant cells as 1 cell). Adverse effects of the material or its degradation products were assessed by material debris accumulation, fatty infiltrations, tissue necrosis, and granuloma-type tissue reactions. Tissue necrosis was characterized as areas with nuclear debris and damaged vessel structures.

The quantity of dermal tissue deposition in the pores of the implants was determined using image analysis software from Leica Microsystems Imaging Solutions as the relative amount of red stained area of the tissue ingrowth area. The digital image of Sirius red stained sections corresponded to an area of $0.65 \times 0.96 \mathrm{~mm}\left(0.625 \mathrm{~mm}^{2}\right)$. All sections were stained in the same session and selection of red areas was identical for each image.

To determine the tissue volume generated, the H\&E stained sections of implant part II were digitally captured using a stereomicroscope. The total surface area was selected and measured using image analysis software from Leica Microsystems Imaging Solutions.

\section{Analyses of PEGT/PBT Copolymer Degradation after Implantation}

Gel permeation chromatography (GPC) was used as a measure for implant degradation to analyze the average MW of the copolymer. First, the surrounding tissue envelope was separated from the remaining copolymer fragments. After mincing, the remaining tissue was extracted in 2 vol 10\% (v.v) acetic acid in chloroform for $16 \mathrm{~h}$ at RT. Samples were filtered $(0.45 \mu \mathrm{m})$ and allowed to evaporate. Subsequently, samples were extracted in $2 \mathrm{vol}$ hexane for $16 \mathrm{~h}$ at RT to remove residual 
fatty tissue. After decantation of excess hexane, polymer samples were dried in a vacuum oven at $50^{\circ} \mathrm{C}$ for $16 \mathrm{~h}$, dissolved in chloroform (Merck)/ hexafluorisopropanol (Aldrich), and eluted through a Waters Styragel Guard precolumn and two PCGel $5 \mu \mathrm{m}$ Mixed-C columns of $30 \mathrm{~cm}$. The flow rate was $1 \mathrm{~mL} / \mathrm{min}$ and a UV detector set at $245 \mathrm{~nm}$ was used. The column temperature was $35^{\circ} \mathrm{C}$ and the sample concentration was $0.03 \%$. The MW was determined relative to polystyrene standards.

The change in molecular composition of the different PEGT/PBT implants was evaluated using ${ }^{1} \mathrm{H}-\mathrm{NMR}$ by comparing the initial spectra before implantation with the ones after that. Spectra were recorded on a Bruker AC 250 operating at $250.1 \mathrm{MHz}$. Chloroform was used as the solvent without internal standard.

\section{Statistical Analysis}

Quantitative data are expressed as the mean $\pm \mathrm{SD}$. As a normal data distribution could not be demonstrated, the Wilcoxon signed-rank test was used for statistical data analysis. A value of $P<0.05$ was considered significant.

\section{RESULTS}

\section{Physicochemical Characteristics of PEGT/PBT Implants}

Similar porous implants having an average porosity of $80 \%$ with interconnecting pores were obtained for all polymer compositions using compression molding and salt leaching. In Figure 2, a scanning electron micrograph illustrates the implant scaffold structure obtained using $500-600 \mu \mathrm{m}$ salt grains. The studied physical properties of the obtained implants with different PEGT/PBT compositions are presented in Table 1. The water-uptake of the different implants increased significantly when longer PEG chains were used in the copolymer compositions and decreased when the weight percentage of the PEGT part increased. The most hydrophilic composition 2000PEGT80PBT20 absorbed a water quantity of more than 8 times its own weight, was very pliable, but almost lost its mechanical stability/strength (hydrogel-like). In contrast, the 300PBT55PBT45 composition had the lowest water uptake, was the least pliable, but supported the best fibroblast cell attachment and growth. Although the 300PEGT70PBT30 composition had similar water-binding capacities as the 300PEGT55PBT45 composition, it clearly supported less fibroblast cell attachment and did not support fibroblast proliferation. Interestingly, the 4000PEGT55PBT45 


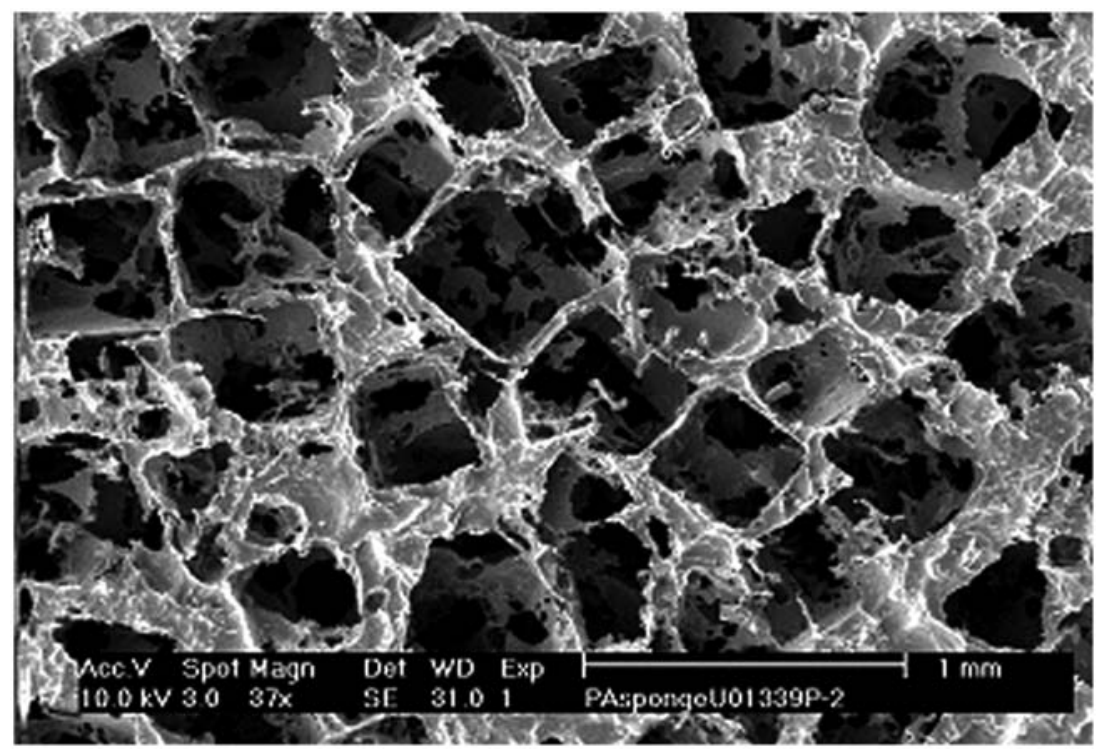

Figure 2. Scanning electron micrographs of compression molded and salt leached implant which was prepared with 300PEGT55PBT45 copolymer and salt grains of sizes ranging from 500 to $600 \mu \mathrm{m}$.

Table 1. Physiochemical characteristics of the implants with different PEGT/PBT compositions ( $a$ PEGTbPBTc $a=M W$ PEG, $b / c=$ weight ratio PEGT/PBT).

\begin{tabular}{lcccc} 
Implant composition & Water-uptake $(\%)^{\mathrm{a}}$ & Pliability $^{\mathrm{b}}$ & Cell Attachment $^{\mathrm{c}}$ & Cell Proliferation $^{\text {c }}$ \\
\hline 300PEGT55PBT45 & $260 \pm 10$ & + & +++ & ++ \\
300PEGT70PBT30 & $250 \pm 70$ & +++ & + & + \\
1000PEGT70PBT30 & $520 \pm 10$ & +++ & 0 & 0 \\
4000PEGT55PBT45 & $490 \pm 10$ & ++ & + & + \\
2000PEGT80PBT20 & $830 \pm 30$ & ++++ & 0 & 0 \\
\hline
\end{tabular}

aWater-uptake (wt\%) is expressed as $\left(m-m_{0}\right) / m_{0}(n=6 \pm S D)$, where $m_{0}$ is the initial weight of the specimen and $m$ the weight after conditioning to equilibrium in PBS.

bPliability of implants after hydratation: 0 not + little ++ moderate +++ intermediate ++++ very.

${ }^{\mathrm{C}}$ Relative number of fibroblast that had attached to the implant after $24 \mathrm{~h}$ or showed proliferation after $96 \mathrm{~h}$ (0 none; + some; ++ moderate; +++ normal).

and 1000PEGT70PBT30 compositions showed a similar degree of water uptake, but the former showed fibroblast attachment, which the latter did not. It has to be noted that attached fibroblasts were not evenly distributed on the polymer surface of the pores, but were clustered on domains of the polymer surface (not shown). All hydrated 
implants had good handling properties except for the 2000PEGT80PBT20 composition.

\section{Macroscopic Evaluations of Porous Implants with Different PEGT/PBT Compositions}

In total, four animals were implanted and after 7 days the bandages were removed. The sites of implantation showed absence of excessive wound edema, skin redness, or irritation. All animals showed normal behavior. They were active, playful, and neither showed excessive itching nor an elevation in body temperature. One year after implantation, the implantation sites were evaluated and scored blindly for abnormal skin color, tissue volume generated, and tissue consistency before and after harvesting of the implants (Table 2).

All implants did not show visible signs of inflammation or differences in skin color compared to surrounding skin. Macroscopically, the tissue volume generated by implants with copolymer composition containing PEG with a MW of 300Da (300PEGT55PBT45, 300PEGT70PBT30) was just visible, but not for the other implants. Further on, one has to consider that the animals' adipose layer had significantly increased (3-4 times) during the study period. The tissue consistency both before and after harvesting, however, showed that most implants were not able to generate supple soft tissue, but scar-like tissue. For the 300PEGT55PBT45, 1000PEGT70PBT30, and 2000PEGT80PBT20 the tissue after excision seemed to contain very hard, small tissue parts indicative of calcifications. Although the 2000PEGT80PBT20

Table 2. Evaluation of implantation sites for skin color, tissue volume generated, and tissue consistency (before and after harvesting of the implants $(n=5)$ ).

\begin{tabular}{|c|c|c|c|c|}
\hline Implant composition & Color $(1-3)^{a}$ & Volume $(0-3)^{\mathrm{b}}$ & $\begin{array}{c}\text { Tissue } \\
\text { consistency } \\
(\text { external })(1-3)^{\mathrm{C}}\end{array}$ & $\begin{array}{c}\text { Tissue } \\
\text { consistency } \\
\left(\text { internal) }(1-3)^{\mathrm{c}}\right.\end{array}$ \\
\hline 300PEGT55PBT45 & 1 & $2.1( \pm 0.36)$ & $2.7( \pm 0.5)$ & $2.7( \pm 0.2)$ \\
\hline 300PEGT70PBT30 & 1 & $1.9( \pm 0.42)$ & $2.2( \pm 0.3)$ & $2.3( \pm 0.2)$ \\
\hline 1000PEGT70PBT30 & 1 & $1.1( \pm 0.24)$ & $2.6( \pm 0.4)$ & $3.0( \pm 0)$ \\
\hline 4000PEGT55PBT45 & 1 & $1.2( \pm 0.32)$ & $2.3( \pm 0.3)$ & $1.9( \pm 0.5)$ \\
\hline 2000PEGT80PBT20 & 1 & 0 & $1( \pm 0)$ & $2.5( \pm 0.5)$ \\
\hline
\end{tabular}

aSkin color: 1 as surrounding skin, 2 light red, 3 dark red/purple.

bTissue volume generated by implant: 1 none as surrounding skin, 2a noticeable, and $3 a$ clear raise in skin height.

${ }^{\mathrm{c}}$ Consistency of the tissue induced by the implant: 1 supple, 2 stiff, and 3 hard fibrotic. 
implantation site appeared supple from the exterior, the internal evaluation revealed that only limited tissue volume was generated.

\section{Histological Evaluations of Porous PEGT/PBT Implants}

After 4 weeks, all implants showed complete tissue ingrowth throughout void spaces of the implant. The host response inside the implant was characterized as a normal response seen at biomaterial surfaces with minimal chemical and physical irritation. The tissue in the pores consisted of giant cells lining the surface of the implant material, proliferating fibro-vascular tissue with macrophages, and some sites with more granulocytes and other lymphocytes. The only consistent difference between implant groups at this time point was the degree of implant fragmentation correlating to implant hydrophilicity. In Figure 3 an overview is presented from the top to bottom of the 300PEGT55PBT45 implant. Interestingly, a clear fibrous capsule that normally surrounds solid implants was not observed for all porous implants. The average vessel diameter, identified with von Willebrand factor staining, was not significantly different between the experimental groups at any time point. However, after 12 weeks, the average vessel diameter in the implants had significantly increased compared to the 4 -week time-point, whereas the number of vessels had decreased. This observation is an indication for physiologically normal vessel maturation after wounding.

All implants were histologically evaluated after 12,26 , and 52 weeks. The implants retrieved after 4 weeks were not included in these analyses, because the host response was still immature with considerable variation in cell density and distribution in implants from the same group. After 12 weeks, the host response had settled, variations within one group of implants were minimal, and differences in tissue reaction between copolymer compositions were more apparent. In the following paragraphs, general histological observations for the different implant groups are described followed by the cellular profile comparison between the implants over time.

The most hydrophobic implants, 300PEGT55PBT45 and 300PEGT70PBT30, showed similar host tissue response over time. In Figure $4 \mathrm{~A}$ and $\mathrm{B}, \mathrm{H} \& \mathrm{E}$ stained sections are shown for the 300PEGT70PBT30 after 12 and 56 weeks, respectively. The tissue response is still characterized by giant cells lining the copolymer surface, but with more mature fibro-vascular tissue in the void spaces when compared to that of 4 weeks. A difference between the 300PEGT70PBT30 and 300PEGT55PBT45 implants was the rate 


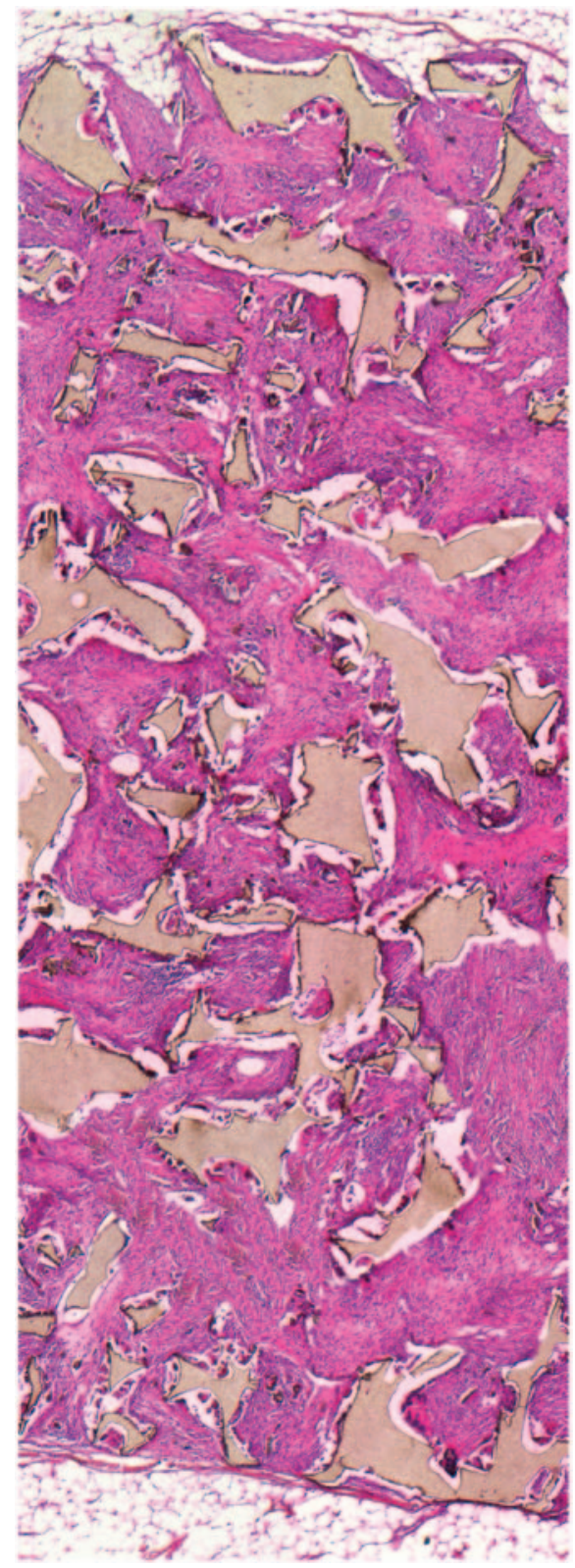

Figure 3. Cross section of 300PEGT55PBT45 implant at 4 weeks stained with H\&E showing an overview from top and bottom. Tissue ingrowth and ECM deposition has occurred in all void spaces. Note the absence of fibrous capsule formation at the edges of the implant. Arrows indicated implant copolymer scaffold. 

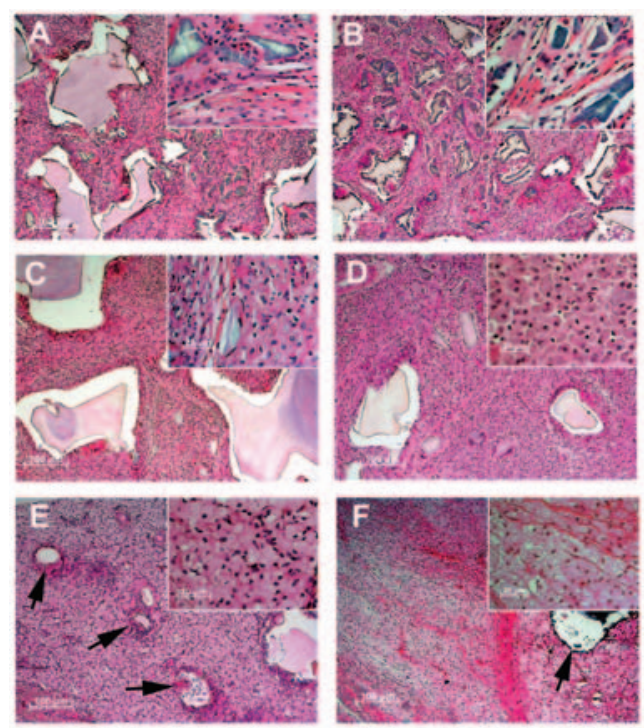

Figure 4. Host response and tissue deposition in 300PEGT70PBT30 (A, B), 4000PEGT55PBT45 (C, D), and 2000PEGT80PBT20 (E, F) implants after 12 (A, C, E) or 52 weeks (B, D, F). The 300PEGT70PBT30 implant showed little fragmentation after 12 and more fragmentation after 52 weeks. The 4000PEGT55PBT45 implant showed after 12 weeks significant fragmentation of parts of the implant with mainly macrophages in the tissue. After 52 weeks most fragments were phagocytized and the remaining larger copolymer showed continuing fragmentation. The 2000PEGT80PBT20 implants was at 12 weeks almost complete fragmented and phagocytized by foam-like cells apart from some calcified copolymer fragments (arrows). After 52 weeks, only more collagen fibers were observed in the tissue.

of fragmentation. After 12 weeks, the backbone of the 300PEGT70PBT30 implant was intact (Figure 4A) and showed increasing fragmentation after 26 and 52 weeks (Figure 4B). The backbone of the 300PEGT55PBT45 implant remained relatively intact up to 26 weeks and only showed considerable fragmentation after 52 weeks.

The 4000PEGT55PBT45 implant showed a more immature loosely organized fibro-vascular tissue with the presence of more granulocytes and macrophages and less collagenous tissue deposition in the void spaces after 12 weeks (Figure 4C). This is likely to be explained by the rapid fragmentation of a part of the implant. In contrast, larger parts of the implants did not show fragmentation up to 52 weeks (Figure 4D). At this time point the void space of the implant was filled with macrophages that had phagocytized small copolymer fragments (insert 
Figure 4D). The amount of deposited ECM and its maturation seem to decrease over time instead of increase.

The extent of tissue response induced by the 1000PEGT70PBT30 implant was in between the 300PEGT70PBT30 and 4000PEGT 55PBT45 implants. After 12 weeks, this implant already showed more extensive fragmentation compared to the 300PEGT70PBT30 implant, but fragments were not as small as found in the 4000PEGT55PBT45 implant. The implant showed continued fragmentation over time and the absence of larger copolymer parts as observed in the 4000PEGT55PBT45 implants. The presence of more copolymer fragments coincided with an increased foreign body response when compared to the 300PEGT70PBT30 implant. However, in comparison with the 4000PEGT55PBT45 implant more fibro-vascular tissue was present, but the increased foreign body response seemed to prevent maturation of the deposited ECM over time.

The 2000PEGT80PBT20 implant behaved differently from the other implants. Already after 4 and 12 weeks most of the implant was completely fragmented into very small copolymer parts (Figure 4E). The fragments were all phagocytized by macrophages that clustered into large areas and appeared as foam-like cells. Some implant fragments could still be observed after 12, 26, and 52 weeks and were calcified (von Kossa stain). These fragments induced a stronger inflammatory response and showed capsule formation (arrows in Figure 4E and F). In time, the amount of thin collagenous ECM fibrils increased, but did not resemble normal fibro-vascular tissue observed with a normal host tissue response. Large areas with foam-like cells were still present after 52 weeks.

The von Kossa staining identified most calcified areas in 1000PEGT70PBT30 followed by 2000PEGT80PBT20 and 4000PEGT 55PBT45. The 300PEGT55PBT45 and 300 PEGT70PBT30 implants did not show any calcification. Moreover, the classical capsule formation around the implants or implant fragments was not observed during the study period except for the 2000PEGT80PBT20 implant.

\section{Cell Numbers and Distribution in PEGT/PBT Implants}

Characterization of the cellular profile in the implants, including total cell number, number of granulocytes, macrophages, giant cells and fibroblastic cells are presented in Figure 5. In all groups, the total cell number per representative area (high power field) was not different between implants after 12 weeks. After 26 weeks, the total cell numbers were comparable to that of 12 weeks, only the 300PEGT55PBT45 
Total cell numbers
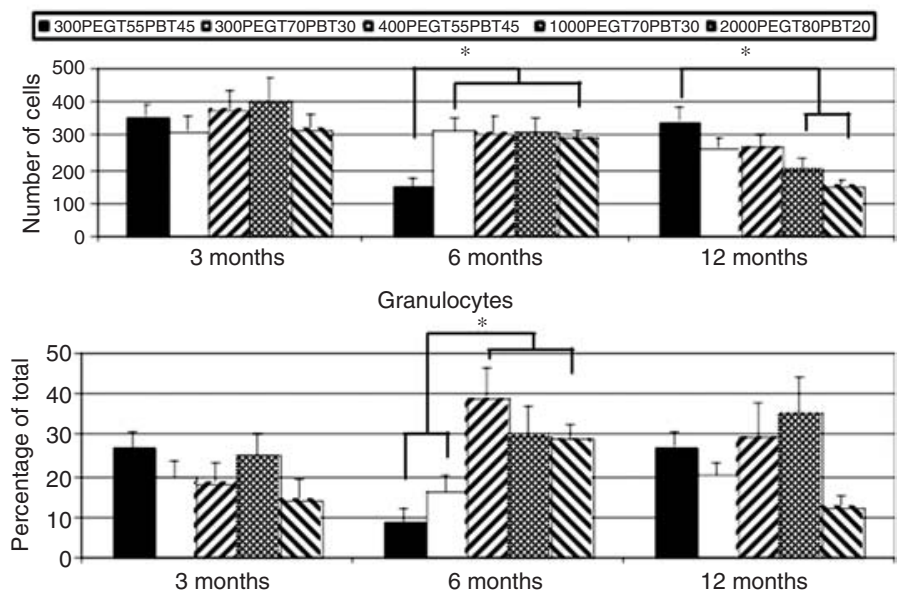

Macrophages

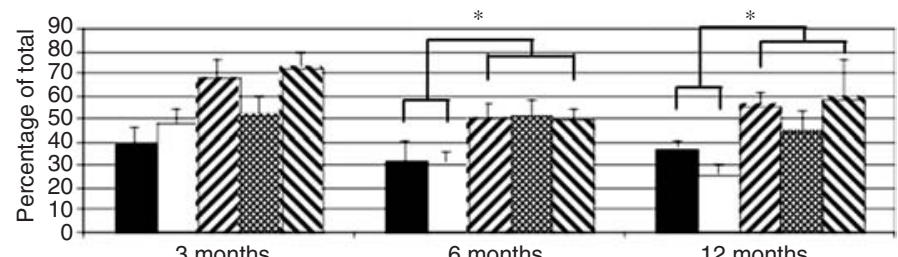

Giant cells

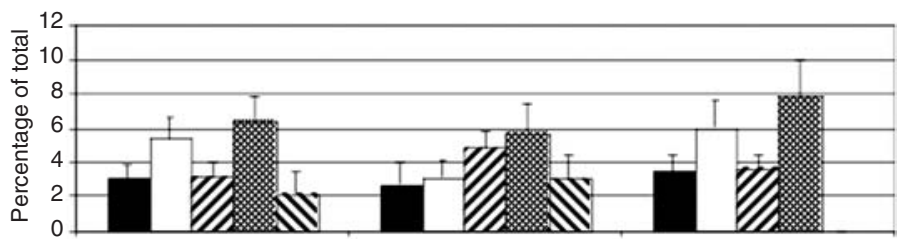

3 months

6 months

12 months

Fibroblasts (vimentin positive)

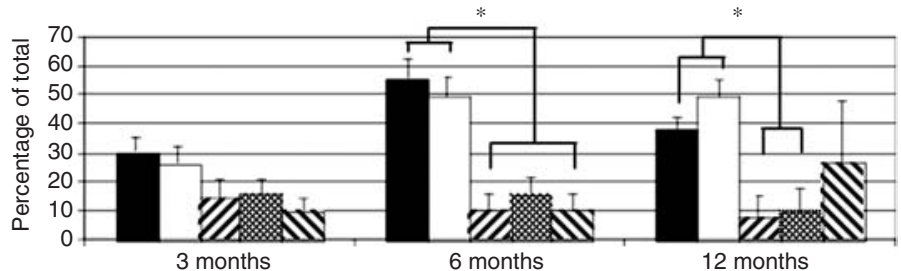

Figure 5. Cell enumerations in the tissue present in the void space of the different implants. The top graph shows the total cell present in the digitized image, whereas the number of granulocytes, macrophages, giant cells, and fibroblasts are shown as percentages of total cell numbers. *Significantly different $(p<0.05$, Wilcoxon signed-rank test). 
implant showed a significant decrease in total cell number compared to the other implants. Surprisingly, after 52 weeks this cell number had increased in the 300PEGT55PBT45 implant and was significantly higher compared to 1000PBT70PBT30 and 2000PEGT80PBT20 implants. After 12 weeks no significant differences were observed for the different cell percentages between the implants. After 26 weeks, the granulocyte and macrophage counts were significantly lower and fibroblast counts significantly higher in the 300PEGT55PBT45 and 300PEGT70PBT30 implants compared to the other implants. After 52 weeks these differences were still present for macrophages and fibroblasts, but not for granulocytes. At this time point, the percentage of granulocytes was the lowest for the 2000PEGT80PBT20 implant, but significant differences were not found due to the high variation. The percentage of giant cells was low and not significantly different among all implants. The giant cells surrounding the remaining few calcified copolymer fragments were observed, but not counted, because these fragments were not present in the digitized images used for cell counting.

\section{Tissue Volume Generation and Quantification of Deposited ECM}

In Figure 6, representative images show the fibro-vascular tissue in all implants after 26 weeks. It is evident that both the 300PEGT55PBT45 and 300PEGT70PBT30 implants (Figure 6A and C) showed more deposition of ECM tissue in the void areas compared to the other implants. In addition, the appearance of this tissue is like normal scar tissue. In the other implants the number of fragments between or phagocytized by macrophages dominates the images.

In Figure 7 , the quantification of the tissue volume generated by the implant is shown in the top graph and the quantity of tissue deposited in the void implant areas in the bottom graph. The tissue volume generated was significantly higher for the slow degrading 300PEGT55PBT45 and 300PEGT70PBT30 implants after 52 weeks. The tissue volume of the 4000PEGT55PBT45 implants decreased over time along with implant degradation. The rapid fragmentation of the 1000PEGT70PBT30 and 2000PEGT80PBT20 implants resulted in collapse of the 3D backbone of the implant and therefore these implants generated significantly smaller tissue volumes compared to the other implants. The amount of collagenous tissue in the implants was comparable for 300PEGT55PBT45 and 300PEGT70PBT30 and both were significantly higher compared to the other three implants. 

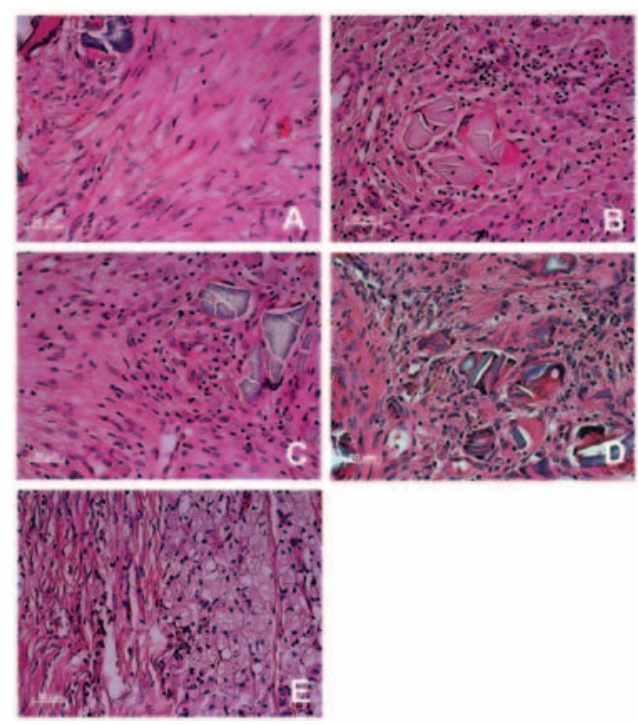

Figure 6. High magnification of $H \& E$ stained tissue showing the difference in ECM deposition and maturation for the different implants after 26 weeks. A. 300PEGT55PBT45, B. 4000PEGT55PBT45, C. 300PEGT70PBT30, D. 1000PEGT70PBT30, and E. 2000PEGT80PBT20.

The latter implants hardly showed presence of Sirius red stained ECM deposition. For all implants a significant increase in the amount of Sirius red stained ECM over time was not observed.

\section{Transmission Electron Microscopy (TEM) Analysis of Implants}

The TEM analysis (not shown) confirmed the histological observations described earlier. Small implant copolymer fragments $0.5-70 \mu \mathrm{m}$ were observed for each implant at each time point. After 52 weeks, the amount of small fragments $(<70 \mu \mathrm{m})$ decreases in the following order 300PEGT55PBT45, 300PEGT70PBT30, 1000PEGT70PBT30, 4000PEGT55PBT45 and 200PEGT80PBT20. The average size of these fragments was declining in reverse order, indicating that the rate of fragmentation seems to correlate with the average size of the copolymer fragments. The giant cells lining the larger copolymer fragments showed a granular cell-copolymer interface like the one previously observed with other biomaterials. The observed foam cells, especially observed in the 2000PEGT80PBT20 implant, contained high number of polymer fragments in their cytoplasm. After 52 weeks, most 

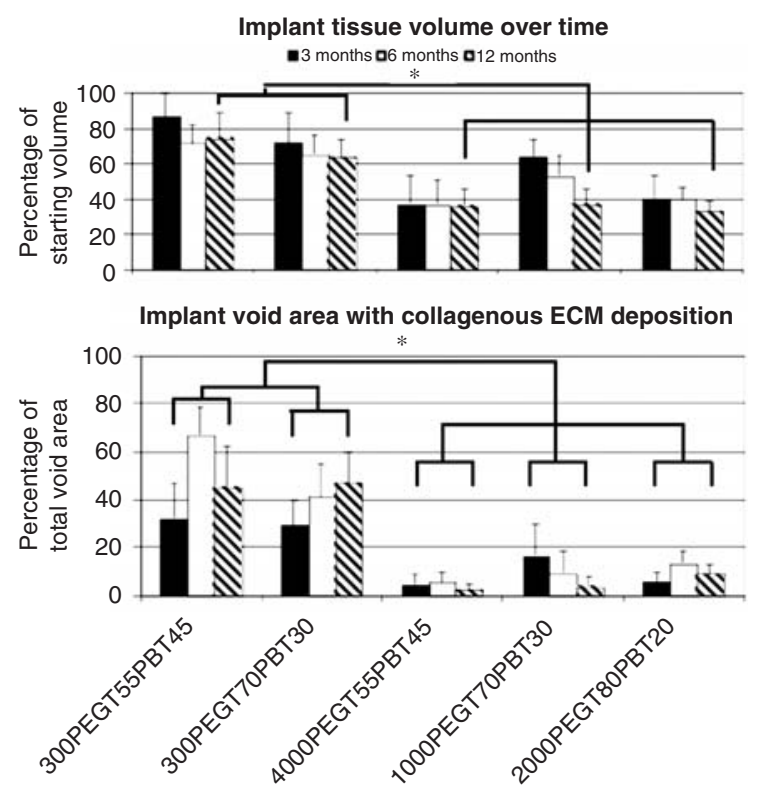

Figure 7. Implant tissue volume generated and the percentage of void implant area filled with collagenous tissue after 12,26 , and 52 weeks for all implants. The latter was identified as red areas in Sirius red stained sections. *Significantly different $(p<0.05$, Wilcoxon signed-rank test).

polymer fragments were rounded and varied in size up till $1 \mu \mathrm{m}$. These foam cells contained dilated rough endoplasmic reticulum, well developed Golgi systems, and multiple mitochondria indicating that these cells are still metabolically active.

\section{Analyses of PEGT/PBT Implant Degradation}

The GPC data showed that after 52 weeks of implantation the average MW of the 300PEGT55PBT45 and 300PEGT70PBT30 copolymers had only decreased by 34 and $37 \%$, respectively (Table 3 ). For the 1000PEGT70PBT30, 4000PEGT55PBT45, and 2000PEGT80PBT20 copolymers it had decreased to $\approx 90 \%$ of its original length. Interestingly, the rapid fragmentation that was observed with histology for the 4000PEGT55PBT45 and 2000PEGT80PBT20 implants correlates with a rapid decrease of $60-64 \%$ in MW measured 4 weeks after implantation. The 1000PEGT70PBT30 showed a decrease in MW of $43 \%$ and the fragmentation rate was in between the rate of the slow degrading and the most rapid degrading implants. The ratio of 
Table 3. Change in copolymer MW and composition after implantation in pigs. Average decrease in $M w(\%)^{a}$ and PEGT/PBT ratio ${ }^{b}$.

\begin{tabular}{|c|c|c|c|c|c|c|c|c|c|c|}
\hline \multirow{2}{*}{$\begin{array}{l}\text { Copolymer } \\
\text { composition }\end{array}$} & \multicolumn{2}{|c|}{$\begin{array}{l}\text { 300PEGT } \\
\text { 55PBT45 }\end{array}$} & \multicolumn{2}{|c|}{$\begin{array}{l}\text { 300PEGT70 } \\
\text { PBT30 }\end{array}$} & \multicolumn{2}{|c|}{$\begin{array}{c}\text { 1000PEGT70 } \\
\text { PBT30 }\end{array}$} & \multicolumn{2}{|c|}{$\begin{array}{l}\text { 4000PEGT } \\
55 \text { PBT45 }\end{array}$} & \multicolumn{2}{|c|}{$\begin{array}{c}\text { 2000PEGT } \\
80 \text { PBT20 }\end{array}$} \\
\hline & $0^{c}$ & $56 / 44^{d}$ & 0 & $67 / 33$ & 0 & $70 / 30$ & 0 & $55 / 45$ & 0 & $80 / 20$ \\
\hline 4 weeks & $3 \pm 0.5$ & $56 / 44$ & $3 \pm 1$ & $65 / 35$ & $43 \pm 4$ & $69 / 31$ & $60 \pm 0.5$ & ND & $64 \pm 5$ & $78 / 22$ \\
\hline 52 weeks & $34 \pm 8$ & $53 / 47$ & $37 \pm 2$ & $59 / 41$ & $90 \pm 3$ & $56 / 44$ & $94 \pm 1$ & $44 / 56$ & $87 \pm 4$ & $65 / 35$ \\
\hline
\end{tabular}

aDecrease in molecular weight is expressed as percentage of MW before implantation and determined by GPC.

${ }^{\mathrm{b}}$ Change in PEGT/PBT or soft to hard ratio was determined by ${ }^{1} \mathrm{H}-\mathrm{NMR}$.

c,d Under each composition the left column indicated the decrease in MW and right column the PEGT/PBT ratio ( $n=4$ for each sample).

Table 4. Summary of functional and biocompatibilty.

\begin{tabular}{lcccc}
\hline & $\begin{array}{c}\text { Handling } \\
\text { properties* }\end{array}$ & $\begin{array}{c}\text { Degradation } \\
\text { at 12 } \text { months* }\end{array}$ & $\begin{array}{c}\text { Tissue reaction } \\
\text { \& quality* }\end{array}$ & $\begin{array}{c}\text { Best performing } \\
\text { composition\# }^{\#}\end{array}$ \\
\hline 300PEGT55PBT45 & 2 & 2 & 3 & 12 \\
300PEGT70PBT30 & 3 & 2 & 3 & 18 \\
1000PEGT70PBT30 & 3 & 3 & 1 & 9 \\
4000PEGT55PBT45 & 2 & 3 & 1 & 6 \\
2000PEGT80PBT20 & 1 & 3 & 1 & 3 \\
\hline
\end{tabular}

${ }^{*}$ Characteristic scored as 1 not optimal, 2 acceptable and 3 close to optimal/best.

${ }^{\#}$ Best performing composition defined by multiplication of the single scores.

PEGT/PBT hardly changed over time for the 300PEGT55PBT45 implants and most for the 2000PEGT80PBT20 implants. The latter showed change in composition from 4 to $1.86 \mathrm{PEGT/PBT}$ ratio. The trend for all copolymer compositions is that soft segment PEGT content decreases more than PBT. Apparently, this segment is more susceptible to degradation than PBT. However, the 1000PEGT70PBT30, 4000PEGT55PBT45, and 2000PEGT80PBT20 showed a decrease of $90 \%$ in the MW, but the remaining implant fragments still showed the presence of a considerable PEGT weight percentage in the composition. This indicates that it is unlikely that only the PBT segment or PBT crystalline domains remain in tissue at later stages of degradation.

\section{DISCUSSION}

In this study porous PEGT/PBT implants with different physicochemical characteristics were evaluated for soft tissue augmentation. 
Long-term biocompatibility ( 52 weeks) of all implants was demonstrated by the absence of wound edema, skin irritation, chronic inflammation, localized tissue necrosis, and granuloma formation. After 4 weeks all implants were completely filled with proliferative fibro-vascular tissue, indicating that the surface properties were not critical for tissue ingrowth into void space of the different implants. The fibrinfibronectin clot in the pores is likely to serve as the 3D-template for tissue ingrowth independent of the ability of cells to adhere to the copolymer surface. The implant geometric structure and degradation/ fragmentation rate had a direct effect on the amount and quality of fibro-vascular tissue. The implant prepared with 300PEGT55PBT45 copolymer, a relative slow degrading polymer, and $500-600 \mu \mathrm{m}$ salt grains showed to be optimal for tissue ingrowth and connective tissue deposition compared to implants prepared with smaller or larger salt grains (submitted for publication).

This study clearly demonstrated that rapid fragmentation increased the induced foreign body response, which is in concordance with observations on other biomaterials $[34,35]$. This increased host response was observed with 4000PEGT55PBT45 and 1000PEGT70PBT30 copolymers and proven by significantly reduced percentages of fibroblasts and increased percentages of macrophages after 26 and 52 weeks. However, the percentage of granulocytes did not increase, which would be a sign for a chronic inflammatory response that can become granulomatous [36,37]. The same holds true for the 2000PEGT80PBT implants, which degraded/fragmented the fastest. The latter implant in contrast to the others induced a different host response with a tissue containing mainly macrophages loaded with many copolymer fragments, referred as 'foam' cells. TEM analysis did however not show cell death or that these foam-like cells were metabolically inactive. Others have demonstrated that phagocytosis of PLLA particles by peritoneal macrophages caused cell damage and necrosis [38]. However, in this study most fragments were rounded and not needle-like, which could explain this difference in observations. With the exception of sporadic, calcified fragments, the 2000PEGT80PBT20 copolymer composition was almost completely degraded. Although speculative, the degradation behavior of 2000PEGT80PBT20 implant could represent an advanced end-stage of degradation for all copolymer compositions.

Expanded polytetrafluoroethylene (ePTFE) and silicone are nondegradable biocompatible materials, but like most implant materials induce a foreign body tissue response and subsequent fibrous capsular formation $[39,40]$. Interestingly, capsular formation around the porous PEGT/PBT implants was not observed. Its absence is likely to favor 
tissue survival and maturation in the central parts of the implant. Usually physicomechanical stress between implant and tissue induces or stimulates capsule formation. Apparently, this was not the case with these implants. Factors contributing to this positive effect could be the implant size, its integration into the adipose tissue or the implantation site, for example within the adipose tissue without any contact to the muscle fascia layer.

The quantity of fibro-vascular tissue in the void implant areas or the percentage of mature connective tissue that stained red using Sirius red proved to be a good discriminating parameter to measure the quality of the host tissue response. For this reason, the 300PEGT70PBT30 seem to perform superiorly compared to the 300PEGT55PBT45 implant. The 300PEGT70PBT30 implant showed a constant rate of fragmentation, whereas the 300PEGT55PBT45 implant showed little fragmentation up to 26 weeks followed by considerable fragmentation after 52 weeks. The latter seems to reverse the tissue response from being the best after 26 weeks to one with an increased host response after 52 weeks as proved by higher total cell number and a decrease in the percentage of connective tissue deposition. In this respect, it would be very interesting to conduct a long-term study in which this PEGT/PBT copolymer showing bulk degradation and fragmentation is compared to a biomaterial that primarily degrades through surface erosion like those based on poly(glycerol sebacate) and poly(anhydrides) [41,42]. Another important question also remains unanswered. Does the formed connective tissue in the adipose tissue remain stable over time? Studies in rats showed that with fast degrading biomaterials, the scarlike tissue remaining after complete degradation of the implant was remodeled and disappeared in time [43]. If this is a species-specific difference between rodents and pigs or a normal phenomenon should be addressed first. If the latter holds true, there would be no perspective to pursue the development of biodegradable soft tissue fillers.

Although biocompatibility has been demonstrated within this study, a satisfactory biofunctionality was not obtained with any implants used. Ideally, an implant should generate new adipose tissue, but this is most likely not attainable for any biomaterials available. As second best, the obtained tissue should have comparable mechanical properties as the tissue site of implantation and sufficient volume. In this study, the implants 300PEGT55PBT45 and 300PEGT70PBT30 generated the highest tissue volumes after 52 weeks and deposited significantly more connective tissue than the other implants, but the tissue consistency was undesirable. It was much stiffer as the surrounding adipose tissue. Interestingly, the tissue consistency was softer in faster degrading 
implants except for the 2000PEGT80PBT20 and 1000PEGT70PBT30 implants, which showed localized copolymer calcifications. These calcification phenomena have been described previously for this copolymer and seems to be related to the ability of the copolymer to take up water [30]. It is surprising that it was not observed for the 4000PEGT55PBT45 implant having a similar water uptake as the 1000PEGT70PBT30 implant. A possible explanation for the lack of calcification of 4000PEGT55PBT45 implant could be that the copolymer architecture is different. It could, for example, contain larger PBT or PEGT rich domains. The domains rich in PEGT fragment quicker, whereas the PBT rich domains are more stable. This explanation would be in agreement with the observed fragmentation pattern of this implant and also explains why fibroblasts only adhered to certain sites on the polymer surface.

PEGT/PBT copolymer degradation has been analyzed in other studies and proceeds mainly via mechanisms of hydrolysis, oxidation, and phagocytosis [15,28-30,44,45]. Deschamps et al. [45] showed not only that during accelerated hydrolysis of the copolymer a decrease in copolymer MW is mainly caused via scission of the ester bonds connecting the PEG and terephthalate, but that cleavage in the PBT hard segment also occurred. Furthermore, Deschamp et al. also showed a faster decrease in the PEG content in rats both for intact and predegraded copolymer compositions resulting in a higher remaining PBT content and an increase in crystallinity. This preference for PEG degradation is in accordance with the results. Apparently, the hard segments containing PBT remain in the body at later stages of degradation. In this respect, the one year follow-up is not long enough. It should be extended to $3-5$ years to not only show long-term functionality of the slower degrading implants with a PEG MW of 300, but also the absence of regression in tissue volume and adverse tissue reactions. Its importance is underscored by the fact that in humans PLA bone implants showed a late adverse tissue response against phagocytized poly(L-)lactide crystalline particles after more than 5 years [46]. Similar results were obtained in a more recent study using predegraded PLA96 after subcutaneous implantation in rats, which proved a suitable alternative to study late degradation reactions [47]. That biofunctionality aspects, such as tissue volume generated and tissue consistency, can be studied by this approach, seems unlikely.

In conclusion, this study demonstrated that the slower degrading implants 300PEGT55PBT45 and 300PEGT70PBT30 performed significantly better in comparison to fast degrading implants, in terms of soft 
tissue biocompatilibility, tissue volume generated, and connective tissue deposition. Nevertheless, appropriate biofunctionality in terms of tissue consistency comparable to surrounding tissue was not obtained. For porous implants, the percentage of fibroblastic cells and mature collagenous tissue deposition proved to be good indicators for the quality of the host tissue response. In this respect, the rate and extent of copolymer fragmentation seems to be a determining factor in the successful soft tissue augmentation using porous PEGT/PBT copolymer implants. Future studies will include follow-ups longer than 52 weeks to warrant that implants do not provoke long-term adverse cellular reactions, maintain the tissue volume generated, and show improved tissue consistency.

\section{ACKNOWLEDGMENTS}

F. Péters is acknowledged for performance of the NMR analyses. This study was sponsored by IsoTis OrthoBiologics.

\section{REFERENCES}

1. Germann, G. and Steinau, H.U. (1996). Breast Reconstruction with the Extended Latissimus Dorsi Flap, Plast. Reconstr. Surg., 97(3): 519-526.

2. Germann, G. and Steinau, H.U. (1996). The Clinical Reliability of Vein Grafts in Free-flap Transfer, J. Reconstr. Microsurg., 12(1): 11-17.

3. Geddes, C.R., Morris, S.F. and Neligan, P.C. (2003). Perforator Flaps: Evolution, Classification, and Applications, Ann. Plast. Surg., 50(1): 90-99.

4. Germann, G., Bickert, B., Steinau, H.U., Wagner, H. and Sauerbier, M. (1999). Versatility and Reliability of Combined Flaps of the Subscapular System, Plast. Reconstr. Surg., 103(5): 1386-1399.

5. Markey, A.C. and Glogau, R.G. (2000). Autologous Fat Grafting: Comparison of Techniques, Dermatol. Surg., 26(12): 1135-1139.

6. Billings, E., Jr. and May, J.W., Jr. (1989). Historical Review and Present Status of Free Fat Graft Autotransplantation in Plastic and Reconstructive Surgery, Plast. Reconstr. Surg., 83(2): 368-381.

7. Anderson, J.M., Bevacqua, B., Cranin, A.N., Graham, L.M., Hoffman, A.S., KLein, M., Kowalski, J.B., Morrissey, R.F., Obstbaum, S.A., and Ratner, B.D. (1996). Implants and Devices, Academic Press Inc., London.

8. Williams, D.F. (1987). Definitions in Biomaterials, Progress in Biomedical Engineering, 4: 1-72.

9. Wake, M.C., Patrick, C.W., Jr. and Mikos, A.G. (1994). Pore Morphology Effects on the Fibrovascular Tissue Growth in Porous Polymer Substrates, Cell Transplant, 3(4): 339-343. 
10. Wake, M.C., Mikos, A.G., Sarakinos, G., Vacanti, J.P. and Langer, R. (1995). Dynamics of Fibrovascular Tissue Ingrowth in Hydrogel Foams, Cell Transplant, 4(3): 275-279.

11. Zeltinger, J., Sherwood, J.K., Graham, D.A. Mueller, R. and Griffith, L.G. (2001). Effect of pore Size and Void Fraction on Cellular Adhesion, Proliferation, and Matrix Deposition, Tissue Eng., 7(5): 557-572.

12. Adams, R.K., Hoeschele, G.K., Witsiepe, W.K. (1996). Thermoplastic Polyether Ester Elastomers, In: Holden, G., Legge, N.R., Quirk, R. and Schroeder, H.E. (eds), Thermoplastic Elastomers, 2nd edn, pp. 191-225, Hansen Publishers, Munich.

13. Harris, J.M. (1992). Introduction to Biotechnical and Biomedical Applications of Poly(ethylene glycol), In: Harris, J.M. (ed.), Poly(ethylene glycol) Chemistry, Biotechnical and Biomedical Applications, pp. 1-12, Plenum Press, New York.

14. Grote, J.J., Bakker, D., Hesseling, S.C. and van Blitterswijk, C.A. (1991). New Alloplastic Tympanic Membrane Material, Am. J. Otol., 12(5): 329-335.

15. Bakker, D., van Blitterswijk, C.A., Hesseling, S.C., Koerten, H.K., Kuijpers, W. and Grote, J.J. (1990). Biocompatibility of a Polyether Urethane, Polypropylene Oxide, and a Polyether Polyester Copolymer. A Qualitative and Quantitative Study of Three Alloplastic Tympanic Membrane Materials in the Rat Middle Ear, J. Biomed. Mater. Res., 24(4): 489-515.

16. Bulstra, S.K., Geesink, R.G., Bakker, D., Bulstra, T.H., Bouwmeester, S.J. and van der Linden, A.J. (1996). Femoral Canal Occlusion in Total Hip Replacement using a Resorbable and Flexible Cement Restrictor, J. Bone Joint Surg. Br., 78(6): 892-898.

17. Radder, A.M., Leenders, H. and van Blitterswijk, C.A. (1995). Bone-bonding Behaviour of Poly(ethylene oxide)-Polybutylene Terephthalate Copolymer Coatings and Bulk Implants: A Comparative Study, Biomaterials, 16(7): 507-513.

18. Wang, H.J., Bertrand-de Haas, M., van Blitterswijk, C.A. and Lamme, E.N. (2003). Engineering of a Dermal Equivalent: Seeding and Culturing Fibroblasts in PEGT/PBT Copolymer Scaffolds, Tissue Eng., 9(5): 909-917.

19. van Dorp, A.G., Verhoeven, M.C., Meij, T.H.N.-V.D., Koerten, H.K. and Ponec, M. (1999). A Modified Culture System for Epidermal Cells for Grafting Purposes: An in vitro and in vivo Study, Wound Repair Regen., 7(4): 214-225.

20. van Dorp, A.G., Verhoeven, M.C., Koerten, H.K., van Blitterswijk, C.A. and Ponec, M. (1999). Bilayered Biodegradable Poly(ethylene glycol)/ Poly(butylene terephthalate) Copolymer (Polyactive) as Substrate for Human Fibroblasts and Keratinocytes, J. Biomed. Mater. Res., 47(3): 292-300.

21. Beumer, G.J., van Blitterswijk, C.A. and Ponec, M. (1994). Biocompatibility of a Biodegradable Matrix used as a Skin Substitute: An in vivo Evaluation, J. Biomed. Mater. Res., 28(5): 545-552.

22. Druecke, D., Langer, S., Lamme, E., Pieper, J., Ugarkovic, M., Steinau, H.U. and Homann, H.H. (2004). Neovascularization of Poly(ether ester) 
Block-copolymer Scaffolds in vivo: Long-term Investigations using Intravital Fluorescent Microscopy, J. Biomed. Mater. Res., 68A(1): 10-18.

23. Wang, H.J., Bertrand-De Haas, M., Riesle, J., Lamme, E. and Van Blitterswijk, C.A. (2003). Tissue Engineering of Dermal Substitutes Based on Porous PEGT/PBT Copolymer Scaffolds: Comparison of Culture Conditions, J. Mater. Sci. Mater. Med., 14(3): 235-240.

24. El-Ghalbzouri, A., Lamme, E.N., van Blitterswijk, C., Koopman, J. and Ponec, M. (2004). The Use of PEGT/PBT as a Dermal Scaffold for Skin Tissue Engineering, Biomaterials, 25(15): 2987-2996.

25. Beumer, G.J., van Blitterswijk, C.A., Bakker, D. and Ponec, M. (1993). Cell-seeding and in vitro Biocompatibility Evaluation of Polymeric Matrices of PEO/PBT Copolymers and PLLA, Biomaterials, 14(8): 598-604.

26. Beumer, G.J., van Blitterswijk, C.A. and Ponec, M. (1994). Degradative Behaviour of Polymeric Matrices in (Sub)Dermal and Muscle Tissue of the Rat: A Quantitative Study, Biomaterials, 15(7): 551-559.

27. Radder, A.M., Leenders, H. and van Blitterswijk, C.A. (1994). Interface Reactions to $\mathrm{PEO} / \mathrm{PBT}$ Copolymers (Polyactive) after Implantation in Cortical Bone, J. Biomed. Mater. Res., 28(2): 141-151.

28. Deschamps, A.A., van Apeldoorn, A.A., Hayen, H., de Bruijn, J.D., Karst, U., Grijpma, D.W. and Feijen, J. (2004). In vivo and in vitro Degradation of Poly(ether ester) Block Copolymers Based on Poly(Ethylene Glycol) and Poly(Butylene Terephthalate), Biomaterials, 25(2): 247-258.

29. van Dijkhuizen-Radersma, R., Hesseling, S.C., Kaim, P.E., de Groot, K. and Bezemer, J.M. (2002). Biocompatibility and Degradation of Poly(ether-ester) Microspheres: in vitro and in vivo Evaluation, Biomaterials, 23(24): 4719-4729.

30. van Blitterswijk, C.A., van den Brink, J., Leenders, H. and Bakker, D. (1993). The Effect of PEO Ratio on Degradation, Calcification and Bone-bonding of PEO/PBT copolymers (PolyactiveR), Cells Materials, 3(11): 23-26.

31. Sullivan, T.P., Eaglstein, W.H., Davis, S.C. and Mertz, P. (2001). The Pig as a Model for Human Wound Healing, Wound Repair Regen., 9(2): 66-76.

32. Hoeschele, G.K. (1997). Thermostabile Polyester-block-copolymere, Die Angew Makromol. Chem., 58/59: 299-319.

33. Lamme, E.N., de Vries, H.J., van Veen, H., Gabbiani, G., Westerhof, W. and Middelkoop, E. (1996). Extracellular Matrix Characterization during Healing of Full-thickness Wounds Treated with a Collagen/elastin Dermal Substitute Shows Improved Skin Regeneration in Pigs, J. Histochem. Cytochem., 44(11): 1311-1322.

34. Turner, J.E., Lawrence, W.H. and Autian, J. (1973). Subacute Toxicity Testing of Biomaterials using Histopathologic Evaluation of Rabbit Muscle Tissue, J. Biomed. Mater. Res., 7(1): 39-58.

35. van Sliedregt, A., Knook, M., Hesseling, S.C., Koerten, H.K., de Groot, K. and van Blitterswijk, C.A. (1992). Cellular Reaction on the Intraperitoneal Injection of Four Types of Polylactide Particulates, Biomaterials, 13(12): 819-824. 
36. Anderson, J.M. and Langone, J.J. (1999). Issues and Perspectives on the Biocompatibility and Immunotoxicity Evaluation of Implanted Controlled Release Systems, J. Control Release, 57(2): 107-113.

37. Morehead, J.M. and Holt, G.R. (1994). Soft-tissue Response to Synthetic Biomaterials, Otolaryngol. Clin. North Am., 27(1): 195-201.

38. Lam, K.H., Schakenraad, J.M., Esselbrugge, H., Feijen, J. and Nieuwenhuis, P. (1993). The Effect of Phagocytosis of Poly(L-lactic acid) Fragments on Cellular Morphology and Viability, J. Biomed. Mater. Res., 27(12): 1569-1577.

39. Batniji, R.K., Hutchison, J.L., Dahiya, R., Lam, S.L. and Williams, E.F. 3rd (2002). Tissue Response to Expanded Polytetrafluoroethylene and Silicone Implants in a Rabbit Model, Arch. Facial Plast. Surg., 4(2): 111-113.

40. Ward, W.K., Slobodzian, E.P., Tiekotter, K.L. and Wood, M.D. (2002). The Effect of Microgeometry, Implant Thickness and Polyurethane Chemistry on the Foreign Body Response to Subcutaneous Implants, Biomaterials, 23(21): 4185-4192.

41. Wang, Y., Kim, Y.M. and Langer, R. (2003). In vivo Degradation Characteristics of Poly(glycerol sebacate), J. Biomed. Mater. Res., 66(1): 192-197.

42. Shastri, V.P., Padera, R.F., Tarcha, P. and Langer, R. (2004). A Preliminary Report on the Biocompatibility of Photopolymerizable Semi-interpenetrating Anhydride Networks, Biomaterials, 25(4): 715-721.

43. Holder, W.D., Jr., Gruber, H.E., Moore, A.L., Culberson, C.R., Anderson, W., Burg, K.J. and Mooney, D.J. (1998). Cellular Ingrowth and Thickness Changes in Poly-L-lactide and Polyglycolide Matrices implanted Subcutaneously in the Rat, J. Biomed. Mater. Res., 41(3): 412-421.

44. Bakker, D., van Blitterswijk, C.A., Hesseling, S.C., Daems, W.T. and Grote, J.J. (1990). Tissue/biomaterial Interface Characteristics of Four Elastomers, A Transmission Electron Microscopical Study, J. Biomed. Mater. Res., 24(3): 277-293.

45. Deschamps, A.A., Claase, M.B., Sleijster, W.J., de Bruijn, J.D., Grijpma, D.W. and Feijen, J. (2002). Design of Segmented Poly(ether ester) Materials and Structures for the Tissue Engineering of Bone, J. Control Release, 78(1-3): 175-186.

46. Bergsma, J.E., de Bruijn, W.C., Rozema, F.R., Bos, R.R. and Boering, G. (1995). Late Degradation Tissue Response to Poly(L-lactide) Bone Plates and Screws, Biomaterials, 16(1): 25-31.

47. De Jong, W.H., Eelco, B.J., Robinson, J.E. and Bos, R.R. (2005). Tissue Response to Partially in vitro Predegraded Poly-L-lactide Implants, Biomaterials, 26(14): 1781-1791. 